\title{
PENGELOLAAN PERPUSTAKAAN SEKOLAH SMAN 1 BUKIT SUNDI DAN SMAN 1 LEMBANG JAYA KABUPATEN SOLOK
}

\author{
Desriyeni*1, Elva Rahmah $^{2}$, Marlini ${ }^{3}$ \\ ${ }^{1,2}$ Universitas Negeri Padang; Jln. Prof. Dr. Hamka Kampus UNP 25131, telp/fax 0751-7053363 \\ ${ }^{3}$ Program Studi Informasi, Perpustakaan dan Kearsipan, Fakultas Bahasa dan Seni, Universitas \\ Negeri Padang \\ e-mail: desriyeni@yahoo.com
}

\begin{abstract}
IbM program aims to provide understanding to partners about the concept and implementation of library management in accordance with library management procedures. The targets to be achieved are as follows. 1) Improving the quality of library staff in managing the library through the manterhadap the nature of the library. A minimum of 75 training materials can be mastered by the trainees. 2) Produce school library management guidelines to facilitate library staff in managing the library. 3) Applying knowledge in school library management. Output target in the form of process is the occurrence of improvement of target audience ability in understanding understanding, concept and process of management and utilization of school library. Output target in the form of product is at least $75 \%$ of participants produce library materials that have been processed and at least $75 \%$ of participants generate library catalogs to facilitate the process of retrieval. The methods offered to solve the problem of library management are: through the creation of a library management module that contains the concepts of library management; socialization and training of school library management. Implementation of the activity begins with the preparation of training materials, copying, presenting the material, and training with individual guidance. To evaluate the achievement of objectives begins by measuring the candidate's initial capability, followed by an evaluation to measure participants' ability at each stage of the activity, and a final evaluation to measure achievement purpose of program activities. Training activities carried out smoothly in accordance with the expected objectives of this program activities. This activity received a positive response from various parties and trainees in the management of school libraries. So it is expected to provide better service and the existence of school library will be more real in the community.
\end{abstract}

Keywords - school library, library management, library training

\section{Abstrak}

Program IbM bertujuan memberikan pemahaman kepada mitra tentang konsep dan pelaksanaan pengelolaan perpustakaan yang sesuai dengan prosedur pengelolaan perpustakaan. Target yang ingin dicapai program ini sebagai berikut. 1) meningkatkan kualitas tenaga perpustakaan dalam melakukan pengelolaan perpustakaan melalui pemaha manterhadap hakikat perpustakaan. Minimal 75 materi pelatihan dapat dikuasai oleh peserta pelatihan. 2) menghasilkan pedoman pengelolaan perpustakaan sekolah untuk memudahkan tenaga perpustakaan dalam melakukan pengelolaan perpustakaan. 3) mengaplikasikan pengetahuan dalam pengelolaan perpustakaan sekolah. Target luaran berupa proses adalah terjadinya peningkatan kemampuan khalayak sasaran dalam pemahaman pengertian, konsepdan proses pengelolaan serta pemanfaatan perpustakaan sekolah. Target luaran berupa produk adalah minimal $75 \%$ peserta menghasilkan bahan pustaka yang sudah diolah dan minimal $75 \%$ peserta menghasilkan catalog perpustakaan untuk memudahkan dalam proses temu kembali. Metode yang ditawarkan untuk menyelesaikan persoalan pengelolaan perpustakaan adalah: melalui pembuatan modul pengelolaan perpustakaan yang berisi konsep-konsep pengelolaan perpustakaan; melakukan sosialisasi dan pelatihan pengelolaan perpustakaan sekolah. Pelaksanaan kegiatan dimulai dengan persiapan materi pelatihan, penggandaan, penyajian materi, dan pelatihan dengan bimbingan individual.Untuk evaluasi ketercapaian tujuan dimulai dengan mengukur kemampuan awal calon peserta, dilanjutkan dengan evaluasi untuk mengukur kemampuan peserta 
pada setiap tahap kegiatan, dan evaluasi akhir dilakukan untuk mengukur ketercapaian tujuan program kegiatan. Kegiatan pelatihan yang dilaksanakan berjalan lancar sesuai dengan tujuan yang diharapkan dari program kegiatan ini. Kegiatan ini mendapat respon yang positif dari berbagai pihak dan peserta pelatihan dalam pengelolaan perpustakaan sekolah. Sehingga diharapkan dapat memberikan pelayanan yang lebih baik dan keberadaan perpustakaan sekolah akan semakin nyata di tengah masyarakat.

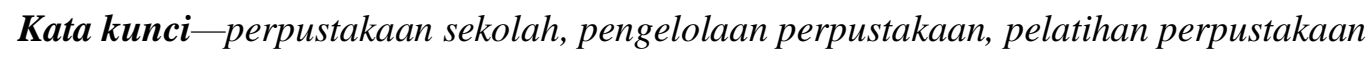

\section{PENDAHULUAN}

Keberhasilan belajar siswa tidak hanya ditentukan dengan beragamnya penerapan model dan metode pembelajaran yang diajarkan. Faktor lain yang menyebabkan terjadinya keberhasilan belajar siswa di sekolah adalah tersedianya sarana dan prasarana pendidikan yang memadai serta pemanfaatan dan pengelolaan yang optimal. Berdasarkan Standar Nasional Pendidikan, setiap sekolah wajib memiliki perpustakaan. Dalam pengelolaannya, perpustakaan harus dikelola dengan tenaga pengelola yang sesuai dan berkompeten di bidangnya. Namun dalam kenyataannya, perpustakaan di sekolah terutama sekolah dasar, dikelola oleh tenaga pengajar.

Sekolah sebagai satuan pendidikan formal, diwajibkan memiliki sumber belajar. Hal ini juga berlaku untuk pendidikan nonformal, baik yang diselenggarakan oleh pemerintah maupun masyarakat (UU No. 20 Tahun 2003 Pasal 45). Sumber belajar ini menjadi tugas tenaga kependidikan, baik pengelola satuan pendidikan, pemilik pamong belajar, pengawasan, peneliti, laborat, teknisi sumber belajar, dan pustakawan. Di antara sumber belajar yang diwajibkan tersebut adalah perpustakaan yang dikelola secara langsung oleh pustakawan.

Sebelum membicarakan bagaimana seharusnya perpustakaan sekolah dikelola dalam rangka mendukung proses pendidikan dan pembelajaran di sekolah, maka ada baiknya mencoba cermati terlebih dahulu pengertian dari perpustakaan. Pengertian perpustakaan berkembang dari waktu ke waktu. Pada abad ke-19 perpustakaan didefinisikan sebagai"suatu gedung, ruangan atau sejumlah ruangan yang berisi koleksi buku yang dipeliharadengan baik, dapat digunakan oleh masyarakat atau golongan masyarakat tertentu.

Secara nyata perpustakaan sekolah merupakan sarana untuk proses belajar dan mengajar bagi guru maupun bagi siswa. Lasa (2009:12) berpendapat bahwa perpustakaan sekolah adalah sistem pengelolaan informasi oleh sumber daya manusia yang terdidik dalam bidang perpustakaan, dokumentasi, dan informasi. Sedangkan, menurut Yusuf (2007:2) perpustakaan sekolah adalah perpustakaan yang ada di lingkungan sekolah. Diadakannya perpustakaan sekolah bertujuan memenuhi kebutuhan informasi bagi masyarakat di lingkungan sekolah yang bersangkutan, khususnya para guru dan siswa yang berperan sebagai media dan sarana untuk menunjang kegiatan proses belajar mengajar di tingkat sekolah. Oleh karena itu, perpustakaan merupakan bagian integral dari program penyelenggaraan pendidikan tingkat sekolah.

Menurut Standar Nasional Indonesia untuk Perpustakaan Sekolah (SNI7329-2009), pengertian perpustakaan sekolah adalah perpustakaan yang berada pada satuan pendidikan formal di lingkungan pendidikan dasar dan menengah yang merupakanbagian integral dari kegiatan sekolah yang bersangkutan, dan merupakan pusat sumberbelajar untuk mendukung tercapainya tujuan pendidikan sekolah yang bersangkutan. Dari beberapa pengertian di atas dapat ditarik kesimpulan bahwa perpustakaan sekolah harus menjadi bagian penting dari tujuan pendidikan di sekolah yang bersangkutan. Hal ini juga menunjukkan bagaimana perpustakaan seharusnya berperan sebagai elemen penting dalam keberhasilan proses pendidikan dan pembelajaran di sekolah. Berdasarkan pendapat di atas dapat kita lihat bahwa perpustakaan sekolah merupakan sebuah tempat yang menyediakan koleksi yang berguna bagi pendidikan di sekolah. Keberadaannya pun menyatu dengan lingkungan sekolah, serta hanya bisa di akses oleh masyarakat sekolah yang bersangkutan.

Menurut Standar Perpustakaan Sekolah (SNI 7329-2009), perpustakaan sekolah bertujuan menyediakan pusat sumber belajar sehingga dapat membantu pengembangan dan peningkatan minat baca, literasi informasi, bakat serta kemampuan peserta didik, Seperti dalam Surachman (2007), apabila kita lebur tujuan tersebut ke dalam fungsi-fungsi yang terdapat dalam 
perpustakaan, maka fungsi perpustakaan sekolah sebagai berikut.

a. Pusat kegiatan belajar-mengajar yang terintegrasi dengan kurikulum di sekolah

b. Pusat penelitian sederhana yang memungkinkan para siswa

c. Mengembangkankreativitas, bakat dan imajinasinya.

d. Pusat kegiatan rekreatif (hiburan) dan pusat peningkatan minat baca

e. Pusat belajar mandiri dan meningkatkan kemampuan literasi informasi bagi siswa.

Tujuan dan fungsi perpustakaan sekolah di atas menegaskan bahwa perpustakaan sekolah harus dapat menjadi bagian integral dalam proses pengembangan pendidikan dan pembelajaran yang dilakukan di sekolah. Hal ini ke depannya akan memberikan jaminan terbentuknya generasi yang terampil belajar sepanjang hayat dan mampu mengembangkan daya pikir agar mereka dapat hidup sebagai warga negara yang bertanggung jawab. Berdasarkan Standar Nasional Pendidikan, setiap sekolah wajib memiliki perpustakaan. Dalam pengelolaannya, perpustakaan harus dikelola dengan tenaga pengelola yang sesuai dan berkompeten di bidangnya, namun dalam kenyataannya, perpustakaan di sekolah terutama sekolah dasar, dikelola oleh tenaga pengajar. Jika dikaitkan dengan proses belajar mengajar di sekolah, perpustakaan sekolah memberikan sumbangan yang sangat berharga dalam upaya meningkatkan aktivitas siswa serta meningkatkan kualitas pendidikan dan pengajaran.

Berdasarkan hasil observasi awal, ternyata banyak sekolah terutama Sekolah Menengah tidak terkecuali SMAN 1 Bukit Sundi dan SMAN 1 Lembang Jaya Kabupaten Solok yang menemukan permasalahan dalam pengembangan perpustakaan sekolah adalah tidak adanya SDM yang mengelola perpustakaan, atau minimnya tenaga perpustakaan. Di sekolah tersebut diamati perpustakaan dikelola oleh guru sebagai pekerja 'sambilan'ini bukannya buruk sama sekali, akan tetapi sering kali menjadikan perpustakaan tidak dapat berkembang dan kehilangan fungsinya sehingga akhirnya tidak dapat mencapai tujuan yang diharapkan.

Tabel 1. Data Kondisi Sekolah SMA Negeri 1 Bukit Sundi Kabupaten Solok

\begin{tabular}{|l|l|c|l|}
\hline No. & \multicolumn{1}{|c|}{ Kondisi } & Jumlah & \multicolumn{1}{c|}{ Keterangan } \\
\hline 1 & Pengelola Perpustakaan & 1 & Berpendidikan SMA \\
\hline 2 & Koleksi & 42.832 & Layak pakai 3.672 \\
\hline 3 & Jenis layanan & 2 & Referensi dan sirkulasi \\
\hline 4 & Siswa & 493 & - \\
\hline 5 & Guru & 51 & 37 guru PNS dan 14 guru honor \\
\hline 6 & Tenaga kependidikan & 7 & - \\
\hline
\end{tabular}

Sumber: Tata Usaha Sekolah SMA Negeri 1 Bukit Sundi Kabupaten Solok

Dari data tabel 1. Dapat terlihat bahwa pengelola di perpustakaan SMA Negeri 1 Bukit Sundi Kabupaten Solok hanya di kelola oleh satu orang yang berlatar belakang SMA. Jika dilihat dari jumlah koleksi yang ada 42.832 eksemplar, tetapi yang layak diguna hanya 3.672 eksemplar. Jenis layanan yang ada di perpustakaan ini adalah layanan sirkulasi dan layanan referensi yang seharusnya bisa di manfaatkan secara maksimal. Jika dilihat dari masyarakat sekolah yang harus dilayani perpustakaan sekolah adalah jumlah 493 siswa, 51 guru dan 7 tenaga kependidikan.

Tabel 2. Data Kondisi Sekolah SMA Negeri 1 Lembang Jaya Kabupaten Solok

\begin{tabular}{|c|l|c|l|}
\hline No. & \multicolumn{1}{|c|}{ Kondisi } & Jumlah & \multicolumn{1}{c|}{ Keterangan } \\
\hline 1 & Pengelola Perpustakaan & 3 & $\begin{array}{l}\text { 1 orang guru tamatan S1 Ekonomi } \\
\text { 2 orang tamatan SMA }\end{array}$ \\
\hline 2 & Koleksi & 14.540 & \\
\hline 3 & Jenis layanan & 2 & Referensi dan sirkulasi \\
\hline 4 & Siswa & 199 & \\
\hline 5 & Guru & 25 & \\
\hline 6 & Tenaga kependidikan & 6 & \\
\hline
\end{tabular}

Sumber: Tata Usaha Sekolah SMA Negeri 1 Bukit Sundi Kabupaten Solok

Dari data tabel 2. Dapat terlihat bahwa pengelola di perpustakaan SMA Negeri 1 Lembang 
Jaya Kabupaten Solok hanya di kelola oleh 3 orang yang terdiri dari satu orang guru dengan tugas tambahan sebagai kepala perpustakaan berlatar belakang pendidikan S1 Ekonomi dan dua orang pengelola perpustakaan berlatar belakang pendidikan SMA. Jika dilihat dari jumlah koleksi yang ada 14.540 eksemplar. Jenis layanan yang ada di perpustakaan ini adalah layanan sirkulasi dan layanan referensi. Jika dilihat dari masyarakat sekolah yang harus dilayani perpustakaan sekolah adalah jumlah 199 siswa, 25 guru dan 6 tenaga kependidikan.

Berdasarkan tabel di atas dapat dilihat jika SDM yang mengelola tidak mempunyai kompetensi dalam pengelolaan perpustakaan. Hal ini akan semakin menghambat perkembangan perpustakaan sekolah. Mengingat pentingnya perpustakaan sekolah, sudah semestinya bahwa SDM ini harus menjadi perhatian apalagi merujuk pada permendiknas nomor 25 tahun 2008 yangmengatur masalah standar tenaga perpustakaan sekolah/madrasah. Dimana didalamnya diatur syarat-syarat minimal bagi SDM yang mengelola perpustakaan, Sehingga SDM yang mempunyai kemampuan dan keahlian sesuai standar adalah menjadi hal yang tidak dapat ditawar lagi apabila sekolah ingin mengembangkan perpustakaan sekolah dengan lebih baik.

Mengenai koleksi yang dimiliki Sekolah Menengah tersebut, buku-buku yang dimiliki minim sekali walaupun ada, tetapi buku-buku lama yang tersedia bukan cetakan terbaru dan sebagian yang bisa di manfaatkan seperti di SMA 1 Bukit Sundi terdapat 42.832 koleksi yang layak pakai hanya 3.672. Merujuk pada Standar Perpustakaan Sekolah dimana perpustakaan bertujuan menyediakan pusat sumber belajar, maka koleksi atau sumber daya koleksi merupakan'nyawa' dari keberadaan perpustakaan sekolah. Koleksi perpustakaan merupakan bagian yang menjadi 'elemen' keberhasilan fungsi dan tujuan perpustakaan sekolah. Di Sekolah tersebut juga diamati bahwa tempat penyimpanan tidak representati, masih tidak beraturan. Bukubuku pun tidak tertata dengan rapi dan tidak sesuai dengan standar yang ditentukan. Sekolah harus mampu memberikan jaminan ketersediaan tempat atau media bagi siswa untuk mendapatkan informasi yang akan memperkaya pengetahuan dan imajinasinya, yang tidak kalah pentingnya tenaga pengolah perlu dilatih/ditatar tentang pengolahan dan pelayanan serta pengadaan bahan pustaka sehingga dapat menunjang dalam kegiatan belajar mengajar.

Pedoman pengelolaan perpustakaan sebetulnya sudah banyak dihasilkan oleh lembagalembaga terkait, namun pelaksanaannya yang belum maksimal bahkan sama sekali tidak dilaksanakan ketika meninjau ke perpustakaan-perpustakaan sekolah. Diperlukan perhatian lebih dari lembaga terkait akan pentingnya pengelolaan perpustakaan terutama perpustakaan yang ada di sekolah/madrasah.

Dalam upaya menunjang pengelolaan perpustakaan sekolah yang berkualitas, salah satu usaha yang dilakukan Dinas Pendidikan adalah menyelenggarakan Lomba Perpustakaan Sekolah Terbaik tingkat Sekolah. Lomba ini diharapkan dapat meningkatkan pengelolaan perpustakaan sekolah yang sesuai dengan standar pengelolaan perpustakaan sekolah. Dari perlombaan yang sudah dilaksanakan beberapa kali, didapatkan informasi bahwa pengelolaan perpustakaan sekolah hanya diberikan perhatian lebih pada saat akan dilaksanakan perlombaan. Setelah perlombaan selesai, pengelolaan perpustakaan tidak lagi diperhatikan secara berkelanjutan.

Dari beberapa sekolah yang telah diobservasi di Kabupaten Solok, Perpustakaan SMAN 1 Bukit Sundi dan SMAN 1 Lembang Jaya Kabupaten Solok pengelolaan perpustakaan sekolah belum dilaksanakan dengan maksimal. Aktivitas di perpustakaan hanya berkisar pada aktivitas peminjaman saja, sementara itu standar pengelolaan perpustakaan yang seharusnya mulai dari pengadaan, pengolahan, pemeliharaan, pelayanan dan promosi tidak dilaksanakan oleh tenaga perpustakaan yang bertugas. Bahan pustaka yang menjadi koleksi perpustakaan diinventarisir ke dalam buku induk tanpa dilengkapi dengan label untuk memudahkan temu kembali ketika koleksi sudah diletakkan di rak. Koleksi juga banyak yang berdebu karena tidak dipelihara dengan baik. Hal ini terjadi karena keterbatasan pengetahuan dari tenaga perpustakaan tentang ilmu perpustakaan.

Pengajuan usulan dari para kepala sekolah untuk mengadakan formasi pustakawan saat penerimaan pegawai baru belum disetujui oleh pemerintah daerah karena adanya anggapan bahwa guru bisa mengelola perpustakaan ketika tidak mengajar, padahal kebutuhan akan tenaga yang profesional di bidang perpustakaan sangat dibutuhkan terutama untuk sekolah mengingat kebiasaan membaca dan melek informasi akan memberikan efek kebiasaan melek terhadap informasi di tingkat usia selanjutnya. Adanya pustakawan yang profesional di sekolah menengah diharapkan 
dapat melaksanakan pengelolaan perpustakaan dengan baik dan berjalannya program-prgram perpustakaan untuk meningkatkan kebiasaananak dalam memiliki keingintahuan terhadap berbagai informasi. Perkembangan teknologi dan informasi saat ini banyak memberikan pengaruh terhadap perubahan kebiasaan anak dalam mengakses informasi. Pemilahan terhadap informasi yang masuk pada sebagian akan tidak terkontrol, sehingga berefek pada sikap dan perilaku yang menyimpang di tengah masyarakat seperti maraknya berita tentang kenakalan anak dan remaja dan memudarnya rasa saling menghormati dan saling menghargai. Disinilah perpustakaan sekolah bisa berperan dalam mendidik siswa agar dapat memberikan informasi-informasi yang bermanfaat dan mengajarkan bagaimana memilih informasi yang berguna untuk para peserta didik di sekolah tersebut.

Perpustakaan sekolah perlu dikelola oleh pustakawan dengan tanggungjawab dan dedikasi yang tinggi terhadap layanan. Pustakawan sekolah harus mempunyai jiwa sabar, serta dituntut untuk memahami apa arti pendidikan sesungguhnya. Pustakawan sekolah juga harus bersifat proaktif dan suka menolong. Siswa yang kurang paham bagaimana cara mengakses sebuah koleksi harus dibantu agar bisa menemukan informasi yang dibutuhkannya dengan cepat dan tepat. Melalui informasi inilah siswa bisa lebih berkiprah dalam meraih prestasi.

Berdasarkan hasil wawancara dengan kepala sekolah dan pengelola perpustakaan SMAN 1

Bukit Sundi dan SMAN 1 Lembang Jaya Kabupaten Solok dapat disimpulkan sebagai berikut.

a. Pengelola perpustakaan sekolah SMAN 1 Bukit Sundi dan SMAN 1 Lembang Jaya Kabupaten Solok membutuhkan cara pengelolaan perpustakaan sekolah sesuai dengan standar perpustakaan sekolah

b. Pengelola perpustakaan sekolah belum memiliki pengetahuan bagai mana mengelola perpustakaan sekolah sesuai dengan standar pengelolaa perpustakaan sekolah

c. Fasilitas untuk melakukan pengelolaan perpustakaan sudah ada tetapi belum di manfaatkan secara maksimal

Berdasarkan analisis situasi di atas, tim dosen Informasi, Perpustakaan dan Kearsipan Fakultas Bahasa dan Seni Universitas Negeri Padang perlu memberikan materi tentang pengelolaan perpustakaan sekolah di SMAN 1 Bukit Sundi dan SMAN 1 Lembang Jaya Kabupaten Solok. Berdasarkan observasi yang telah dilakukan SMAN 1 Bukit Sundi dan SMAN 1 Lembang Jaya Kabupaten Solok permasalahan permasalahan yang temui sebagai berikut.

a. Pengelola perpustakaan sekolah belum sesuai dengan standar pengelolaan perpustakaan sekolah

b. Siswa dan guru sebagaian besar belum memanfaatkan perpustakaan sebagai sumber belajar dengan baik

Melihat kondisi tersebut, maka Tim pengabdian kepada masyarakat memandang perlu diselenggarakan sebuah program memberikan bantuan dalam bentuk pelatihan pengelolaan perpustakaan sekolah. Dalam kegiatan ini akan dipecahkan permasalahan secara tuntas mulai dari pemahaman konsep dan melakukan praktik pengelolaan perpustakaan sekolah.

\section{METODE}

Berdasarkan berbagai permasalahan mitra program IbM yang telah diuraikan sebelumnya, maka metode yang ditawarkan untuk menyelesaikan persoalan pengelolaan perpustakaan dan telah disepakati bersama Tim Pelaksana Program IbM UNP dengan SMAN 1 Bukit Sundidan SMAN 1 Lembang Jaya KabupatenSolokmelalui beberapa tahapan sebagai berikut. Pertama, membuat modul pengelolaan perpustakaan yang berisi konsep-konsep dalam pengelolaan perpustakaan yaitu: hakikat perpustakaan sekolah, pengembangan koleksi, pengolahan koleksi (klasifikasi dan katalogisasi), layanan perpustakaan sekolah, pemeliharaan koleksi perpustakaan sekolah, tata ruang dan perlengkapan perpustakaan sekolah, staf perpustakaan sekolah/madrasah dan literasi informasi, pembinaan dan pengembangan minat baca. Kedua, melakukan sosialisasi dan pelatihan pengelolaan perpustakaan untuk tenaga perpustakaan sekolah di SMAN 1 Bukit Sundidan SMAN 1 Lembang Jaya. Pelatihan tahap pertama berisi materi pemahaman kepada tenaga perpustakaan tentang perpustakaan sebagai pusat sumber belajar dan informasi dan pelaksanaan proses pengembangan koleksi perpustakaan. Setelah pelatihan, tenaga perpustakaan ditugaskan untuk 
langsung mengaplikasikan ilmu yang sudah didapat pada pelatihan tahap pertama di perpustakaan masing-masing pada hari-hari berikutnya dan akan dievaluasi pada pelatihan tahap berikutnya. Ketiga, melakukan pelatihan tahap kedua yaitu proses pengolahan bahan pustaka mulai dari klasifikasi sampai pembuatan katalog perpustakaan. Selain itu juga diberikan juga pengetahuan tentang bentuk-bentuk lain dari pengolahan bahan pustaka. Serta melakukan pelatihan yang mencakup pemeliharaan, pelayanan dan promosi perpustakaan agar tenaga perpustakaan secara berkelanjutan dapat mengelola perpustakaan untuk meningkatkan kualitas pengelolaan perpustakaan setiap waktu.

\section{HASIL DAN PEMBAHASAN}

Perpustakaan sekolah merupakan perpustakaan yang berada dalam suatu sekolah. Dengan adanya perpustaaan sekolah diharapkan dapat menjadi pengaruh yang signifikan terhadap kualitas pendididkan. Perpustakaan sekolah SMAN 1 Bukit Sundi dan SMAN 1 Lembang Jaya Kabupaten Solok dalam upaya pengembangan kualitas penyelenggaran proses belajar mengajar disekolah, keberadaan perpustakaan sudah menjadi kebutuhan yang tidak mungkin ditawar-tawar lagi.

Perhatian pemerintah besar terhadap perpustakaan sekolah, tetapi tidak diimbangi dengan pengembangan dan pembinaan yang serius terhadap tenaga pengelolanya. Hal ini dapat dilihat dari koleksi perpustakaan sekolah belum dikelola dengan baik dan perpustakaan sekolah belum diberdayakan secara maksimal. Jadi tidak mengherankan apabila perpustakaan sekolah tidak memberikan kontribusi yang signifikan terhadap pencapain tujuan sekolah. Hal ini dapat disebabkan oleh berbagai hal mulai dari sumber daya manusia pengelola perpustakaan sekolah, terbatasnya dana rutin yang dialokasikan untuk perpustakaan, kurangnya perhatian dari pimpinan sekolah dan belum adanya program pemerintah yang terencana dan berkesinambungan dalam pengembangan perpustakaan sekolah.

Untuk itu perlu dilakukan kegiatan pelatihan pengelolaan perpustakaan sekolah. Kegiatan pelatihan pengelolaan perpustakaan sekolah berbentuk Ipteks bagi Masyarakat Pengelolaan Perpustakaan Sekolah SMAN 1 Bukit Sundi dan SMAN 1 Lembang Jaya Kabupaten Solok yang dilaksanakan dapat membantu pengelolaan perpustakaan sekolah sesuai dengan standar pengelolaan perpustakaan sekolah dari materi teori dan praktik yang diberikan instruktur.

Kegiatan di awali dengan membuat modul pengelolaan perpustakaan yang berisi konsepkonsep dalam pengelolaan perpustakaan yaitu hakikat perpustakaan sekolah, pengembangan koleksi, pengolahan koleksi (klasifikasi dan katalogisasi), layanan perpustakaan sekolah, pemeliharaan koleksi perpustakaan sekolah, tata ruang dan perlengkapan perpustakaan sekolah, staf perpustakaan sekolah/madrasah dan literasi informasi, pembinaan dan pengembangan minat baca.

Melakukan sosialisasi dan pelatihan pengelolaan perpustakaan untuk tenaga perpustakaan sekolah di SMAN 1 Bukit Sundi dan SMAN 1 Lembang Jaya. Pelatihan tahap pertama berisi materi pemahaman kepada tenaga perpustakaan tentang perpustakaan sebagai pusat sumber belajar dan informasi. Dari kegiatan ini ditemukan banyak koleksi perpustakaan sekolah tidak bisa dimanfaatkan lagi dan buku-buku yang tersedia tidak sesuai dengan kurikulum hal ini disebabkan sering bergantinya kurikulum. Setelah pelatihan, tenaga perpustakaan ditugaskan untuk langsung mengaplikasikan ilmu yang sudah didapat pada pelatihan.

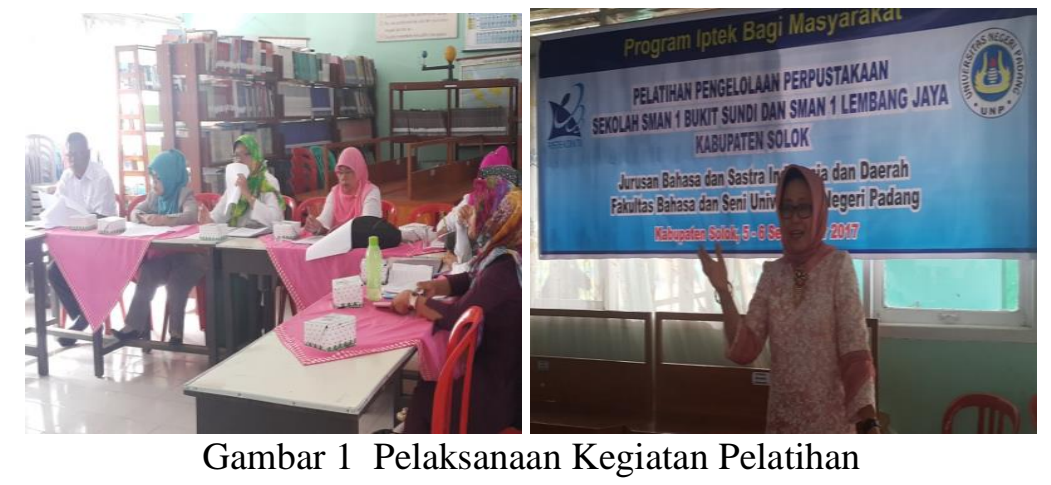


Selanjutnya melakukan pelatihan proses pengolahan bahan pustaka mulai dari klasifikasi sampai pembuatan katalog perpustakaan sekolah. Bentuk bahan pustaka yang digunakan di sekolah ini dapat dilihat atas dua kategori yaitu buku teks pelajaran atau buku paket dan buku referensi. Jadi koleksi yang diolah di kegiatan ini adalah buku paket karena sebagai besar koleksi kedua perpustakaan sekolah ini adalah buku paket. Untuk pengadaan buku ini melalaui dana BOS buku, yang merupakan subsidi langsung ke sekolah.

Selain itu juga diberikan pengetahuan tentang bentuk-bentuk lain dari pengolahan bahan pustaka. Dilanjutkan materi yang mencakup pemeliharaan, pelayanan dan promosi perpustakaan agar tenaga perpustakaan secara berkelanjutan dapat mengelola perpustakaan untuk meningkatkan kualitas pengelolaan perpustakaan setiap waktu. Meningkatkan pemahaman mengenai literasi informasi. Literasi informasi di sekolah merupakan kemampuan mengakses, memahami dan menggunakan sesuatu secara cerdas melalui berbagai aktivitas, antara lain membaca, melihat, menyimak, menulis dan berbicara. Pengelola perpustakaan sekolah diharapkan dapatmenumbuh kembangkan budaya literasi disekolah dan dapat memberikan kesadaran terutama kepada siswa sebagai pemustaka akan keterampilan dalam mencari dan menggunakan informasi, sehingga waktu yang mereka sediakan untuk ke perpustakaan dapat bermanfaat untuk mendapatkan informasi dalam mendukung proses pemberlajaran.

Literasi informasi yang dilaksanakan disekolah SMAN 1 Bukit Sundi dan SMAN 1 Lembang Jaya Kabupaten Solok baru berada pada tahapan pembiasaan. Tahapan pembiasaan menumbuhkan minat baca melalui kegiatan 15 menit membaca sesuai dengan Permendikbud No. 23 Tahun 2015. Tujuan kegiatan literasi di tahap pembiasaan adalah meningkatkan rasa cinta baca di luar jam pelajaran, meningkatkan kemampuan memahami bacaan, meningkatkan rasa percaya diri sebagai pembaca yang baik dan menumbuhkembangkan penggunaan berbagai sumber bacaan. Diharapkan dapat ditingkatkan ketahap pengembangan dan tahap pembelajaran. Tahap pengembangan setelah kegiatan membaca 15 menit diikuti dengan tindakan mendorong peserta didik untuk menunjukkan keterlibatan pikiran dan emosinya dengan proses membaca melalaui kegiatan produktif secara lisan maupun tulisan. Tahap pembelajaran adalah meningkatkan kemampuan literasi di semua mata pelajaran, menggunakan buku pengayaan dan strategi membaca di semua mata pelajaran. Ditahap ini buku yang dibaca berupa buku tentang pengetahuan umum, kegemaran , minat dan juga dapat dikaitkan dengan mata pelajaran tertentu (ada tagihan yang sifatnya akademis).

Tingginya tingkat kehadiran peserta pelatihan (tenaga perpustakaan dan guru pengelola perpustakaan sekolah) dan dukungan berbagai pihak dalam kegiatan pengabdian kepada masyarakat ini tidak terlepas dari pendekatan yang baik oleh tim pelaksanaa kegiatan. Diringi pula oleh komitmen dari dinas pendidikan dan kepada sekolah dalam meningkatkan pengelolaan perpustakaan sekolah.

Kegiatan pengabdian kepada masyarakat khususnya di bidang pengelolaan perpustakaan sekolah perlu terus dilakukan dan melibatkan berbagai pemangku kepentingan melalui pendekatan yang baik. Kegiatan pengelolaan perpustakaan sekolah yang dilakukan dapat semakin difokuskan melalui kegiatan pengabdian pada masyarakat pada suatu bidang kegiatan pengelolaan perpustakaan sekolah. Untuk itu, sasaran kegiatan perlu terus didampingi dengan melaksanakan kegiatan-kegiatan yang lebih spesifik. Berdasarkan penyebab perpustakaan sekolah kurang memberikan kontribusi yang signifikan terhadap pencapaian tujuan sekolah adalah perpustakaan sekolah tidak dikelola dengan baik sesuai dengan standar yang diharuskan. Oleh karena itu perlu dilakukan pengembangan dan pembinaan yang serius terhadap pengelolaan perpustakaan sekolah terutama oleh pihak sekolah.

Pengelola perpustakaaan sekolah, kepala sekolah maupun dinas pendidikan perlu menjalin kerjasama dan komunikasi intensif dengan perguruan tinggi dalam meningkatkan pengelolaan perpustakaan sekolah. Perguruan tinggi terutama Program Studi Informasi Perpustakaan dan Kearsipan dan Program Studi Perpustakaan dan Ilmu Informasi, Fakultas Bahasa dan Seni, Universitas Negeri Padang dapat membantu menghubungkan dengan berbagai pihak dalam memberikan pengayaan pengetahuan dalam pengelolaan perpustakaan sekolah melalui pelatihan. 


\section{KESIMPULAN}

Berdasarkan hasil pelaksanaan pengabdian kepada masyarakat berupa pelatihan pengelolaan perpustakaan sekolah yang telah dilaksanakan dapat disimpulkan sebagai berikut: (1) kegiatan pengabdian kepada masyarakat yang dilaksanakan memberikan manfaat bagi peserta pelatihan terutama dalam meningkatkan pengetahuan dan konsep pengelolaan perpustakaan sekolah ; (2) kegiatan pelatihan dalam hal pengelolaan perpustakaan sekolah dapat dijadikan sarana sharing pengetahuan konseptual pengelolaan perpustakaan sekolah dengan praktek pelaksanaan pengelolaan perpustakaan sekolah dalam kenyataannya; (3) Salah satu permasalahan yang sering dikeluhkan oleh para petugas pengelola perpustakaan sekolah adalah terbatasnya kegiatan pelatihan dan bahan bacaan yang dapat membantu para petugas perpustakaan dalam memahami cara pengelolaan perpustakaan sekolah; dan (4) tingginya tingkat kehadiran peserta pelatihan (tenaga perpustakaan dan guru pengelola perpustakaan sekolah) dan dukungan berbagai pihak dalam kegiatan pengabdian pada masyarakat ini tidak terlepas dari pendekatan yang baik oleh tim pelaksanaa kegiatan.

\section{SARAN}

Berdasarkan kesimpulan tersebut, maka saran yang diajukan dari kegiatan pengabdian kepada masyarakat sebagai berikut. (1) bagi pengelola perpustakaan sekolah diharapkan mau menerapkan pengetahuan dan keterampilan yang telah diperolehnya pada saat pelatihan pengelolaan perpustakaansekolah; (2) kegiatan pengabdian kepada masyarakat khususnya di bidang pengelolaan perpustakaan sekolah perlu terus dilakukan dan melibatkan berbagai pemangku kepentingan melalui pendekatan yang baik; (3) kegiatan pengelolaan perpustakaan sekolah yang dilakukan dapat semakin difokuskan melalui kegiatan pengabdian pada masyarakat pada suatu bidang kegiatan pengelolaan perpustakaan sekolah. Untuk itu, sasaran kegiatan perlu terus didampingi dengan melaksanakan kegiatan-kegiatan yang lebih spesifik, dan (4) berdasarkan penyebab perpustakaan sekolah kurang memberikan kontribusi yang signifikan terhadap pencapaian tujuan sekolah adalah perpustakaan sekolah tidak dikelola dengan baik sesuai dengan standar yang diharuskan. Oleh karena itu perlu dilakukan pengembangan dan pembinaan yang serius terhadap pengelolaan perpustakaan sekolah terutama oleh pihak sekolah.

\section{UCAPAN TERIMA KASIH}

Penulis mengucapkan terima kasih kepada Pimpinan LP2M UNP beserta jajarannya, Pimpinan Fakultas Bahasa dan Seni, dan Mitra dan para peserta kegiatan.

\section{DAFTAR PUSTAKA}

[1] Bafadal, Ibrahim. 2008. PengelolaanPerpustakaanSekolah. Jakarta: BumiAksara.

[2] Darmono. 2007. PerpustakaanSekolah: PendekatanAspekManajemendan Tata Kerja. Jakarta: PT Grasindo.

[3] Indonesia. PerpustakaanNasional RI.PedomanPerpustakaanSekolah IFLA/UNESCO.Jakarta: 2006.

[4] Lasa. 2009. ManajemenPerpustakaanSekolah. Yogyakarta: Pinus.

[5] Sinaga, Dian. 2011. MengelolaPerpustakaanSekolah. Bandung: Bejana.

[6] Suherman. 2009. PerpustakaansebagaiJantungSekolah. Bandung: MQS Publishing.

[7] Undang-UndangNomor 20 Tahun 2003 TentangSistemPendidikanNasional.UndangUndangNomor 43 Tahun 2007 TentangPerpustakaan.

[8] Yusuf, Pawit M. 2007. PedomanPenyelenggaraanPerpustakaanSekolah. Jakarta: Kentana. 